RESEARCH NOTE

\section{Stained Smears as a Source of DNA}

\section{Jackeline Alger*/+, Martha C Acosta, Caterin Lozano, Carmelita Velasquez, Luz Angela Labrada}

\author{
Corporación CIDEIM, Avenida 1N No.3-03, Cali, \\ Colombia *Department of Tropical Medicine, Tulane \\ University School of Public Health and Tropical \\ Medicine, 1501 Canal Street, New Orleans, Louisiana \\ 70112, USA
}

Key words: Plasmodium vivax - Mycobacterium tuberculosis - Leishmania (Viannia) panamensis DNA extraction - PCR - stained-smears

The molecular biological analysis of infectious agents requires the availability of a reliable source of microorganisms to be used to recover DNA. Clinical samples can be obtained directly from infected patients or can be propagated using in vitro or in vivo systems. However, not infrequently, the repeated sampling from patients is not possible because, among other reasons, the procedure is invasive or fastidious, the treatment has been initiated, the patients do not accept the repetition of the procedure or it is not possible to locate them again. Moreover, the in vitro culture of some microorganisms is not possible (e.g. Plasmodium vivax) or requires weeks to months (e.g. Mycobacterium tuberculosis). Neither do all laboratory settings have access to animal models for in vivo systems. Several procedures for DNA extraction from stained specimens and paraffin-embedded tissues have recently been reported. These procedures have yielded DNA from microbial agents in blood stained smears containing $P$. vivax (RS Witzig, RH Barker 1994 Trans R Soc Trop Med Hyg 88: 198) or $P$. falciparum parasites (M Kimura et al. 1995 Mol Biochem Parasitol 70: 194-197); stained tis-

This work received financial assistance from UNDP/ World Bank/WHO TDR (Grant 930872), and TMRC grant IP50-AI30603 from the U.S. National Institute of Health.

+Corresponding author. Fax: (504) 587-7313

Received 8 January 1996

Accepted 23 April 1996 sue sections and cytological smears containing, respectively, herpesvirus (GT Nahass et al. 1995 Arch Dermatol 131: 805-808) and human papillomavirus (AM de Roda Husman et al. 1995 Br J Cancer 72: 412-417); and from formalin-fixed, paraffin-embedded tissues containing mycobacteria (HH Popper et al. 1994 Clin Microbiol Infect Dis 101: 738-741, KJ Sung et al. 1993 Internat J Dermatol 32: 710-713) or Leishmania aethiopica (T Laskay et al. 1995 Trans $R$ Soc Trop Med Hyg 89: 273-275). The advantages of such a procedure include: (1) use of the sample to make both the microscopic and the molecular studies, and (2) the possibility of conducting retrospective studies from archival samples, especially from unusual or rare pathologies.

We here report the results of the recovery and amplification of microbial DNA from fixed and stained clinical samples including blood, sputum and tissue fluid.

DNA was extracted from Field-stained $P$. vivax thick smears (Malaria Control Program Clinic in Florencia, Caqueta and Cali, Colombia), ZiehlNeelsen-stained sputum smears containing $M$. tuberculosis (Corporación CIDEIM), and Giemsastained smears of tissue fluid and inflammatory exudate containing Leishmania (Viannia) panamensis amastigotes (Corporación CIDEIM) using a $5 \%(\mathrm{wt} / \mathrm{vol})$ solution of Chelex- $100^{\mathrm{R}}(\mathrm{K}$ Kain et al. 1992 Am J Trop Med Hyg 46: 473-479, Bio-Rad-Richmond, CA) as follows: $500 \mu \mathrm{l}$ of $1 \%$ Saponin (Sigma-St.Louis, MO) in water was added to $1.5 \mathrm{ml}$ Eppendorf tubes containing sample material obtained by scrapping the surface of the stained smear using a razor blade. Samples were incubated on ice for $60 \mathrm{~min}$, vortexed 3-4 times and centrifuged for 4 min at $12,000 \mathrm{x}$ g at room temperature. After discarding the supernatant, the pellets were washed in PBS (pH 7.2) until the supernatants were clear, usually 2-3 times. Following the addition of $50 \mu \mathrm{l}$ of $5 \%$ (wt/vol) Chelex$100^{\mathrm{R}}$, the samples were vortexed, incubated at $56^{\circ} \mathrm{C}$ for $15 \mathrm{~min}$, vortexed again, and incubated in boiling water for $10 \mathrm{~min}$. After centrifuging at 12,000 $\mathrm{x} \mathrm{g}$ for $4 \mathrm{~min}$, the supernatant (sometimes colored bluish) was collected and stored at $-20^{\circ} \mathrm{C}$ until used. Refer to the Table for primer description and amplification conditions. All reactions included the use of $5 \mu \mathrm{l}$ of extracted DNA and were performed on a MJ Research PTC-100 cycler at Corporación CIDEIM.

All samples containing parasites were amplified by the specific set of primers. The Fig. shows the different PCR products analyzed on agarose gel electrophoresis and stained with ethidium bromide. PCR experiments included the following: 

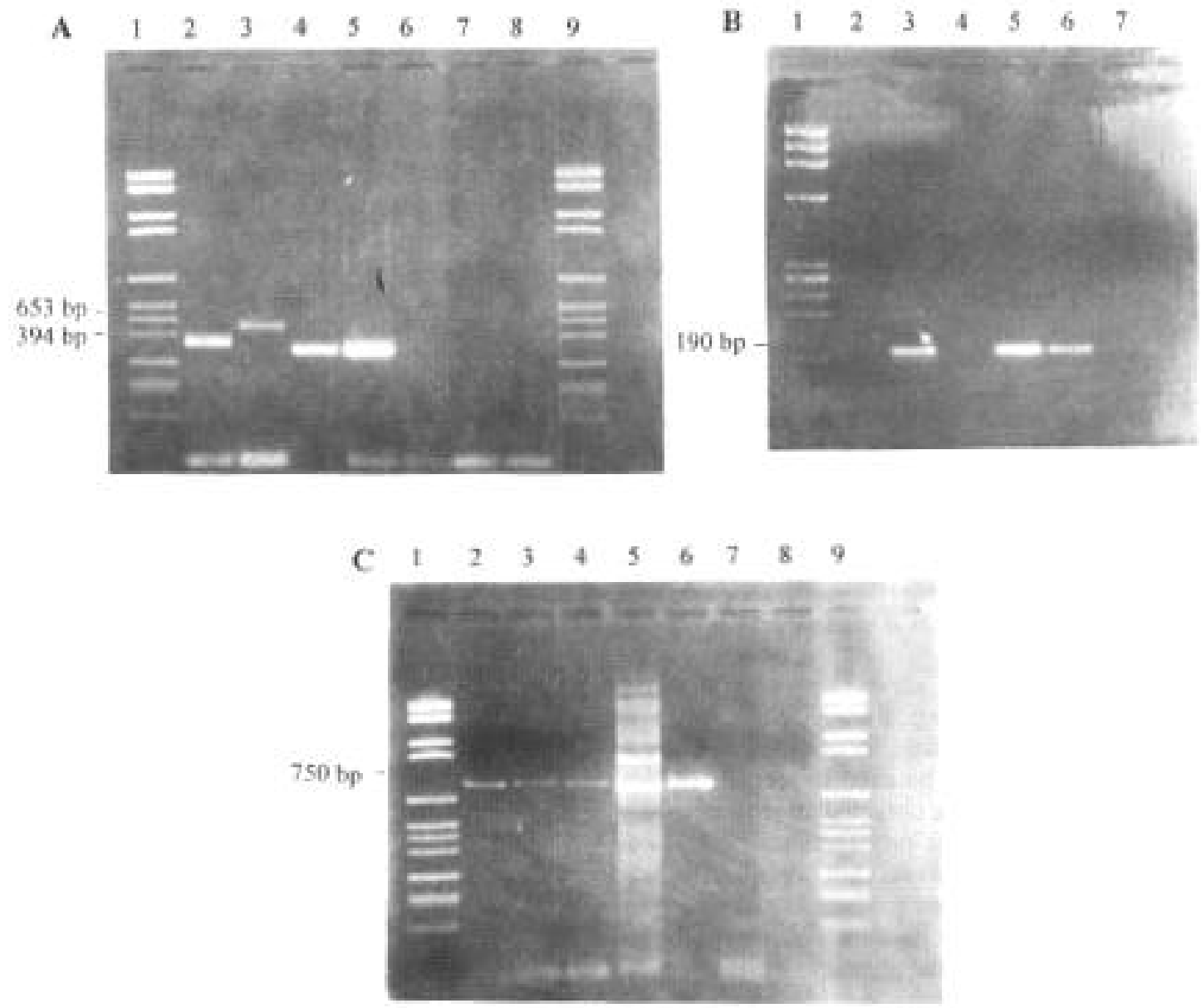

A. Field-stained Plasmodium vivax thick smears. Lanes 1,9: molecular weight (MW) standard. Lane 2: 3 parasites/100 white blood cells (WBC). Lane 3: 132 parasites/100 WBC. Lane 4: 54 parasites/100 WBC. Lane 5: filter paper blot (50 $\mu 1$ of blood) of specimen in Lane 4. Lane 6: microscopically negative stained-smear. Lane 7: filter paper sample of negative specimen. Lane 8: reaction control. B. Ziehl-Neelsen-stained Mycobacterium tuberculosis sputum smears. Lane 1: MW standard. Lane 2: reaction control. Lane 3: $50 \mathrm{fg}$ of purified $M$. tuberculosis DNA. Lane 4: microscopically negative stained smear. Lane 5: stained smear with $>10$ bacilli/field. Lane 6: stained smear with <1 bacilli/field. Lane 7: M. fortuitum stained smear. C. Giemsa-stained Leishmania $(V)$ panamensis smears. Lanes 1,9: MW standard. Lanes 2-4: three stained smears with low amount of amastigotes. Lane 5: stained smear with moderate amount of amastigotes. Lane 6: $1 \mathrm{fg}$ of purified L. (Viannia) kDNA. Lane 7: microscopically negative stained-smear. Lane 8: reaction control.

TABLE

Primers used in PCRs

\begin{tabular}{|c|c|c|c|}
\hline Primers & $\begin{array}{l}\text { Gene } \\
\text { (amplified fragment) }\end{array}$ & $\begin{array}{l}\text { Amplification } \\
\text { conditions }\end{array}$ & Reference \\
\hline $\begin{array}{l}\text { P. vivax } \\
\text { MSP-1 5' } \\
\text { MSP-1 } 33^{\prime}\end{array}$ & $\begin{array}{l}\text { MSP-1 } \\
\text { (polymorphic) } \\
\text { Size fragment } \\
\text { range } 300-480 \mathrm{bp}\end{array}$ & $\begin{array}{l}\text { Denaturing (D): } 96^{\circ} \mathrm{C} \\
\text { Annealing (A): } 66^{\circ} \mathrm{C} \\
\text { Extension (E): } 72^{\circ} \mathrm{C} \\
\text { Cycles: } 35\end{array}$ & $\begin{array}{l}\mathrm{J} \text { Alger et al. } \\
\text { manuscript in } \\
\text { preparation. }\end{array}$ \\
\hline $\begin{array}{l}\text { M. tuberculosis } \\
\text { T4 - 5' } \\
\text { T5 - 3' }\end{array}$ & $\begin{array}{l}\text { IS6110 } \\
\text { (conserved) } \\
\text { Size fragment } \\
190 \mathrm{bp}\end{array}$ & $\begin{array}{l}\text { D: } 95^{\circ} \mathrm{C} \\
\text { A: } 68^{\circ} \mathrm{C} \\
\text { E: } 72^{\circ} \mathrm{C} \\
\text { Cycles: } 35\end{array}$ & $\begin{array}{l}\text { KD Eisenach et al. } \\
\text { 1991 Am Rev Respir } \\
\text { Dis 144: 1160-1163. }\end{array}$ \\
\hline $\begin{array}{l}\text { L. (V.) panamensis } \\
\quad \text { B1 - 5' } \\
\text { B2 - 3' }\end{array}$ & $\begin{array}{l}\text { Minicircle kDNA } \\
\text { (conserved) } \\
\text { Size fragment } \\
750 \mathrm{bp}\end{array}$ & $\begin{array}{l}\text { D: } 95^{\circ} \mathrm{C} \\
\text { A: } 60^{\circ} \mathrm{C} \\
\text { E: } 72^{\circ} \mathrm{C} \\
\text { Cycles: } 35\end{array}$ & $\begin{array}{l}\text { MHL de Bruijn \& DC } \\
\text { Barker } 1992 \text { Acta Trop } \\
\text { 52: 45-58. }\end{array}$ \\
\hline
\end{tabular}


purified target DNA, microscopically negative smear, a smear of other etiology, microscopically positive smear, and a reaction control tube (without target DNA). There was not cross contamination as shown by the results obtained with the negative control specimens. We have compared the results obtained by extracting DNA from $P$. vivax Giemsa-stained thin blood smears and Field-stained thick smears from the same patient and obtained a more intense signal from the thick smear which contains more parasites (data not shown). Similar results were obtained when using stained smears containing different numbers of $M$. tuberculosis bacilli or Leishmania amastigotes. Furthermore, the different stains did not interfere with the reaction.
The use of saponin has improved our results and the PBS washings have not precluded efficient DNA extraction as has been previously reported (Kimura loc.cit). Our results show that stainedsmears are a readily available source of DNA of adequate quality and quantity for use in PCR. This resource offers an alternative to molecular studies requiring clinical samples, and facilitates the application of new technologies to diagnosis when microscopy does not allow a sensitive detection or does not allow a complete identification of the etiologic agent.

Acknowledgements: to Dr Nancy G Saravia for insightful review of the manuscript and to the Colombian Malaria Control Program in Caquetá and Cali for their assistance with sample collection. 
Smear as Source of DNA - Jackeline Alger et al. 